РЕФОРМИРОВАНИЕ ПЕРВИЧНОЙ МЕДИКО-САНИТАРНОЙ ПОМОЩИ В РОССИИ

М. Г. Карайланов, И. Т. Русев, Д. Н. Борисов, О. Ю. Баканев, И. Г. Прокин ФГБВОУ ВО «Военно-медицинская академия имени С. М. Кирова» МО РФ, г. СанктПетербург, Россия

\title{
REFORM OF PRIMARY HEALTH CARE IN RUSSIA
}

\section{G. Karaylanov, I. T. Rusev, D. N. Borisov, O. Yu. Bakanev, I. G. Prokin}

S. M. Kirov Military Medical Academy the Russian Defense Ministry, Saint Petersburg, Russia

Резюме. Изучены исторический отечественный опыт организации первичной медико-санитарной помощи населению крупных городов, становление данного вида медицинской помощи как основной и наибольший раздел системы отечественного здравоохранения, этапы реформирования первичной медико-санитарной помощи до настоящего времени с постепенным переходом к системе медицинского страхования с целью дальнейшего повышения доступности и качества медицинской помощи. Благодаря недавно прошедшей модернизации в системе здравоохранения амбулаторнополиклинические учреждения были укомплектованы современным инновационным медицинским оборудованием для оказания первичной медикосанитарной помощи на высоком уровне. Кроме того, исторически доказана эффективность медицинского обслуживания населения по территориальноучастковому принципу, который определяет и повышает доступность медицинской помощи, с последующим направлением к узким специалистам (библ.: 20 ист.).

Ключевые слова: доступность медицинской помощи, первичная медикосанитарная помощь, реформирование.

Статья поступила в редакцию 20.01.2017.

Summary. Explore the historical domestic experience of primary health care 
to the population of major cities, the establishment of this type of medical care as the main and the largest national healthcare system partition stages of the reform of primary health care to date, with a gradual transition to a system of health insurance in order to further increase the availability of and quality of care. Due to the recent modernization of the health system outpatient offices were equipped with modern innovative medical devices for the delivery of primary health care at a high level. In addition, historically proved the effectiveness of medical care at the district territorial principle, which defines and improves access to health care, with subsequent referral to narrow specialists (bibliography: 20 refs).

Key words: accessibility of care, primary health care, reform.

\section{Article received 20.01.2017.}

На современном этапе реформирования здравоохранения и развития амбулаторно-поликлинических учреждений важным является изучение отечественного опыта организации первичной медико-санитарной помощи (ПМСП) населению в России, так как до настоящего времени весьма актуальными остаются вопросы доступности и качества медицинской помощи. Все мероприятия в действующей системе здравоохранения направлены на повышение доступности и качества оказываемой медицинской помощи населению. Немаловажным в данной проблеме является изучение медицинского обслуживания населения по территориально-участковому принципу, который является основой организации ПМСП в амбулаторных условиях. Исторический опыт развития, реформирования и становления ПМСП в России важен для последующего совершенствования всей системы здравоохранения в целом.

Необходимо отметить, что развитие городской медицины в России началось в XVIII в., когда в 1737 г. медицинской канцелярией был подготовлен 
Указ «О содержании в знатных городах лекарей с производством им жалованья из ратуш». Спустя год был учрежден «особенный для бедных врач», а в 1775 г. при губернских управлениях были созданы приказы общественного призрения, которые занимались организацией и контролем деятельности больниц и сиротских приютов. Задача лечения «временно приходящих», т. е. амбулаторных, больных была поставлена перед больницами приказов общественного призрения лишь в середине XIX в. [1, 2].

Первая в России городская поликлиника возникла в 1804 г. в г. Юрьеве (ныне Тарту, Эстония), где при терапевтической клинике медицинского факультета университета были организованы амбулаторный прием и посещение больных на дому студентами и преподавателями. Одновременно в том же 1804 г. в Санкт-Петербурге силами Медико-филантропического комитета был разработан передовой для того времени проект «домового призрения» больных. По этому проекту помощь на дому и амбулаторный прием пациентов осуществлялись так называемыми частными врачами, за каждым из которых была закреплена одна из частей (районов) города. Таким образом, именно тогда в Петербурге было положено начало участковому принципу амбулаторно-поликлинической помощи, который эффективно действует и по сей день [2].

В 1836 г. в Петербургской медико-хирургической академии была впервые открыта нештатная амбулаторная клиника для приходящих больных, впоследствии амбулаторные клиники были организованы при различных академических кафедрах и госпиталях.

В 1864 г. в России были учреждены земские самоуправления, а вслед за ними в 1870 г. — городские общественные управления, которым поручалась организация медицинской помощи в городах. По ряду причин городская медицина развивалась медленно, значительно отставая от земской [1].

Особенно эффективная система такой помощи действовала в СанктПетербурге. Большая заслуга в ее организации принадлежит С. П. Боткину, который, возглавляя с 1861 г. терапевтическую клинику Медико-хирургической 
академии, уделял большое внимание амбулаторным приемам и считал целесообразным обучать терапии слушателей последнего курса непосредственно в поликлинике на практике $[1,2]$.

В 80-х гг. XIX в. по инициативе С. П. Боткина, избранного гласным нннгородской думы и фактически руководившего медицинским делом в столице, был разработан проект организации амбулаторной помощи бедному населению. Город был разделен на участки; к каждому участку были прикреплены врачи, названные думскими, осуществлявшие бесплатную помощь больным на дому и амбулаторный прием. Врач консультировал пациентов и назначал лечение; в необходимых случаях больные госпитализировались.

На основе опыта организации амбулаторной помощи в Санкт-Петербурге в 1905 г. правление Пироговского общества представило на съезде доклад об основных началах врачебно-санитарного строя в городах. В докладе указывалось, что внебольничная врачебная помощь должна быть по возможности децентрализована. Город должен быть разделен на участки с амбулаторией в центре каждого из них. Амбулатории необходимо размещать в приспособленных помещениях, они должны иметь достаточный запас медикаментов, инструментов и прочих медицинских средств для обследования и лечения больных. Амбулаторный прием и выдача лекарств должны быть бесплатными [3].

В начале XX в. в 35\% городов России вовсе не было внебольничной врачебной помощи, а помощь на дому была организована лишь в 15\% городов. Во всех городах, за исключением Петербурга и отчасти Москвы, амбулаторная помощь была неспециализированной и нередко оказывалась в антисанитарных условиях. Подавляющее большинство городского населения, в том числе в Петербурге и Москве, вообще не пользовалось услугами врачей. Частнопрактикующие врачи обслуживали в основном состоятельных городских жителей. В связи с этим амбулаторная помощь населению городов России до 1917 г. оценивается как крайне незначительная [4, 5]. 
В первые годы строительства советского здравоохранения (1917-1919 гг.) многие принципы организации медицинской помощи населению имели декларативный характер, но уже в 1920 г. был разработан конкретный план мероприятий по развертыванию внебольничной помощи населению страны. В Москве за год количество амбулаторий возросло от 15 до 46, была организована помощь на дому; сеть амбулаторных учреждений развертывалась не только в столицах, но и в других городах. Впервые был поставлен вопрос о внедрении диспансерного метода в работу амбулаторных учреждений [6].

Новые формы внебольничной помощи наиболее активно внедрялись в Москве, а именно в 1922 г. в городе были созданы так называемые амбулаторные объединения: вокруг крупной амбулатории (больничной или внебольничной) сосредоточивались небольшие фабрично-заводские и коммунальные амбулатории, пункты первой помощи на предприятиях и пункты помощи на дому. Радиус территории, обслуживаемой каждым объединением, не превышал 1-1,5 км. Всего было создано 27 объединений, 13 из них - на базе больничных учреждений и $14-$ на базе внебольничных амбулаторий [4]. Уже в Ленинграде в 1928 г. было создано Путиловское здравобъединение, обслуживавшее район с населением 100 тыс. человек, в состав которого входили все лечебно-профилактические учреждения (ЛПУ) района. К 1930 г. в Ленинграде функционировали уже четыре подобных объединения. Участковым врачам придавались в помощь врачи-диспансеризаторы, а также фтизиатры, венерологи, психиатры для наблюдения за своими контингентами $[1,7]$.

В Москве такие объединения получили название единых диспансеров. Отмечается, что чрезмерное увлечение диспансеризацией в ущерб лечебной работе в 1920-х гг. затрудняло деятельность амбулаторных учреждений и ухудшало поликлиническое обслуживание городского населения. Все это послужило поводом для принятия в 1927 г. Наркомздравом положения об амбулаториях, в котором последние определялись как ЛПУ, призванные осуществлять оказание лечебной помощи приходящим больным, а также организацию и проведение профилактических мероприятий среди 
обслуживаемого ими населения.

Важную роль в развитии сети поликлиник сыграл приказ Наркомздрава СССР от 04.08.1938 г. «Об улучшении внебольничной помощи и о мерах по снижению заболеваемости». Возросла доступность амбулаторной помощи для населения: в 1940 г. в городах показатель посещаемости составил в среднем 6,5 на 1 человека в год против 1,3 в 1913 г. [2, 8].

Великая Отечественная война прервала работу по развитию ПМСП. В послевоенные годы развитие внебольничной помощи заключалось главным образом в количественном росте сети ЛПУ. В 1947 г. на совещании актива работников здравоохранения было констатировано низкое качество лечебнопрофилактической помощи, вызванное разобщенностью в работе стационарных и амбулаторно-поликлинических учреждений. Был издан приказ Минздрава СССР № 431 от 24.10 .1947 г. «О мероприятиях по улучшению лечебнопрофилактического обслуживания городского населения», которым утверждалась инструкция по объединению городских больниц с поликлиниками.

Данная реорганизация, начатая в 1947 г., была в основном закончена к 1950 г. В частности, в Ленинграде объединение больниц и поликлиник было завершено уже к 1948 г. В результате реорганизации сети здравоохранения количество участков в объединенных поликлиниках города возросло с 243 до 302, а население на каждом участке сократилось с 4200 до 3500 человек. Это позволило уменьшить нагрузку на врача с 24 до 7 больных. Повысился процент госпитализации, более рационально стал использоваться коечный фонд. Однако при объединении больниц и поликлиник был допущен ряд ошибок, и впоследствии в 1954 г. от него отказались, особенно в крупных городах, поскольку такое объединение ограничивало доступность амбулаторной помощи для пациентов, а у врачей из-за необходимости ежедневной работы в стационаре сокращалось время поликлинического приема $[9,10]$.

В 1960 г. был издан приказ Минздрава СССР № 321 «О состоянии и мерах по дальнейшему улучшению амбулаторно-поликлинического 
обслуживания городского населения», в котором подчеркивалось, что ведущее место в системе медицинского обслуживания населения принадлежит поликлиническим учреждениям [11]. В 1962 г. поликлиники были вновь включены в номенклатуру учреждений здравоохранения, и 1960-е гг. отмечены быстрым ростом сети поликлиник $[12,13]$.

Опыт земской и советской медицины в организации ПМСП был одобрен Всемирной организацией здравоохранения (ВО3) и взят за основу при разработке ее концепции для всех стран, что нашло отражение в АлмаАтинской декларации [14]. В сентябре 1978 г. ВОЗ и Детский фонд ООН (UNICEF, United Nations Childrens Fund) провели историческую международную конференцию по ПМСП в Алма-Ате. Конференция приняла Алма-Атинскую декларацию и стратегию «Здоровье для всех», которая содержала призыв к созданию систем здравоохранения, основанных на ПМСП, гарантирующих равный доступ к медицинскому обслуживанию для всех граждан. В Алма-Атинской декларации ВОЗ впервые в истории провозгласила всеобщее право на здоровье и приоритет ПМСП в развитии мирового здравоохранения.

Многие развитые и развивающиеся страны мира приняли национальные стратегии, отражающие фундаментальные принципы данной декларации. Указанные стратегии до сих пор составляют базис здравоохранения многих стран, функционируя на основе философии Алма-Атинской декларации.

В 1970-1980-х гг. активно осуществлялись мероприятия по расширению специализации амбулаторно-поликлинической помощи. В приказе Минздрава СССР от 23.09.1981 г. № 1000 «О мерах по совершенствованию организации работы амбулаторно-поликлинических учреждений» предусматривалась организация в городских поликлиниках крупных городов специализированных отделений (кабинетов) по различным профилям [15].

В середине 1980-х гг. в отечественном здравоохранении сложилась крайне неблагоприятная ситуация. Финансирование здравоохранения осуществлялось по остаточному принципу, и объем его не превышал $3,3 \%$ от 
валового внутреннего продукта [16]. При этом более 80\% общего объема финансирования здравоохранения приходилось на стационарное звено (против 35-50\% в странах с передовыми системами здравоохранения), т. е. при общем недофинансировании здравоохранения поликлиники финансировались по принципу остатка $[17,18]$.

Для решения перечисленных серьезных проблем, стоящих в тот период перед руководителями здравоохранения, необходимо было разработать и внедрить новые подходы к экономическому планированию в системе здравоохранения. Вскоре был издан приказ Минздрава РСФСР № 1344 от 31.12.1987 г. «Об организации эксперимента по отработке новых форм планирования, управления и финансирования в здравоохранении Ленинграда, Куйбышевской и Кемеровской областей». В марте 1988 г. было утверждено «Временное положение о территориальном медицинском объединении». Этот эксперимент в здравоохранении был основан на принципах экономического планирования развития отрасли. Принцип хозяйственного взаиморасчета лечебных учреждений, по сути означавший создание внутреннего рынка медицинских услуг, стимулировал развитие системы тарифообразования, подушевого финансирования и идеи фондодержания на базе субъекта ПМСП [19].

В крупных городах многие территориальные поликлиники для взрослого и детского населения, женские консультации, а иногда и диспансеры были включены в состав территориальных медицинских объединений [7, 20]. Такая система действует и по сей день.

Подводя итог, важно отметить, что благодаря внедрению нового хозяйственного механизма был продемонстрирован большой потенциал поэтапного реформирования государственной системы здравоохранения и возможности ее существенного усовершенствования. По сути, это явилось первым этапом реформирования здравоохранения с постепенным переходом к медицинскому страхованию, которое в 1991 г. было введено Законом Российской Федерации (РФ) «О медицинском страховании граждан в 
Российской Федерации», а впоследствии 323-Ф3 от 21.11.2011 г. «Об основах охраны здоровья граждан в Российской Федерации» и 326-Ф3 от 29.11.2010 г. «Об обязательном медицинском страховании в Российской Федерации». Таким образом, РФ постепенно перешла к страховой медицине и в последние годы достигла значительного экономического роста, в результате чего было существенно увеличено финансирование отрасли здравоохранения, а также созданы перспективы ее дальнейшего развития.

В рамках ПМСП шире стали проводиться профилактические осмотры отдельных категорий граждан, иммунопрофилактика, осуществлялись внедрение и развитие стационарозамещающих технологий с лекарственным обеспечением больных в рамках гарантированного объема бесплатной медицинской помощи.

Планомерно проводимая Министерством здравоохранения РФ работа существенно повысила уровень обеспеченности населения услугами здравоохранения, увеличился объем профилактических, оздоровительных мероприятий; кроме того, повысились эффективность и качество диспансеризации больных, уровень временной и стойкой утраты трудоспособности снизился за счет расширения гарантированного объема бесплатной медицинской помощи. Также предусмотрены обеспечение доступности медицинской помощи и повышение оперативности оказываемых услуг населению, в том числе сельским жителям. Очень важно понимать, что от состояния ПМСП зависят эффективность и качество деятельности всей системы здравоохранения, решение большинства медико-социальных и экономических проблем.

Изучив исторический опыт развития и реформирования ПМСП в России, можно сделать следующие выводы:

1. Развитие сети медицинских организаций, оказывающих медицинскую помощь в амбулаторных условиях, способствует приближению первичной медико-санитарной помощи к населению и повышению ее доступности, при этом развитие данного вида помощи на базе имеющихся стационаров 
производит противоположный эффект.

2. Медицинские организации, оказывающие амбулаторную помощь, в своем составе имеют меньшую по объему диагностическую базу по сравнению со стационарами. В настоящее время благодаря недавно прошедшей модернизации в системе здравоохранения амбулаторно-поликлинические учреждения были укомплектованы современным инновационным медицинским оборудованием для оказания ПМСП на высоком уровне.

3. Исторически доказана эффективность медицинского обслуживания населения по территориально-участковому принципу, который определяет и повышает доступность медицинской помощи, с последующим направлением к узким специалистам.

\section{СПИСОК ЛИТЕРАТУРЫ / REFERENCES}

1. Egorysheva I. V. Formation of rural and urban medicine: similarities and differences. Problemy sotsial'noy gigieny, zdravookhraneniya i istorii meditsiny. 2007; 1: 56-8. Russian (Егорышева И. В. Становление земской и городской медицины: сходство и различия. Проблемы социальной гигиены, здравоохранения и истории медицины. 2007; 1: 56-8).

2. Mirskiy M. B. Medicine Russia X-XX centuries: Essays on History. Moscow: ROSSPEN; 2005. 631. Russian (Мирский М. Б. Медицина России X-XX веков: очерки истории. М.: РОССПЭН; 2005. 631).

3. Egorysheva I. V., Sherstneva E. V. Moscow City medical and sanitary organization at the beginning of the XX century. Problemy sotsial'noy gigieny, zdravookhraneniya i istorii meditsiny. 2006; 5: 50-2. Russian (Егорышева И. В., Шерстнева Е. В. Московская городская врачебносанитарная организация в начале XX века. Проблемы социальной гигиены, здравоохранения и истории медицины. 2006; 5: 50-2).

4. Ashurkov E. D., Barsukov M. I., Morozov N. N. Essays on the history of the USSR Health (1917-1956). Moscow: Medgiz; 1957. 394. Russian (Аиурков Е. Д., Барсуков М. И., Морозов Н. Н. Очерки истории здравоохранения 
СССР (1917-1956 гг.). М.: Медгиз; 1957. 394).

5. Ivanov M. V. Reform of outpatient services in the region. Problemy sotsial'noy gigieny, zdravookhraneniya i istorii meditsiny. 2007; 5: 30-2. Russian (Иванов М. В. Реформирование амбулаторно-поликлинической службы в регионе. Проблемы социальной гигиены, здравоохранения и истории медицины. 2007; 5: 30-2).

6. Shchepin O. P., Nechaev B. C., Filatov V. B. Russian Health Care Reform Issues. Problemy sotsial'noy gigieny, zdravookhraneniya i istoriya meditsiny. 1998; 2: 3-5. Russian (Щепин О. П., Нечаев В. С., Филатов В. Б. Проблемы реформирования здравоохранения Российской Федерации. Проблемы социальной гигиены, здравоохранения и истории медицины. 1998; 2: 3-5).

7. Sinyavskiy $V$. M. A system of statistical accounting and management in outpatient service. Glav. vrach. 2011; 5: 67-76. Russian (Синявский В. М. О системе статистического учета и управления в амбулаторнополиклинической службе. Глав. врач. 2011; 5: 67-76).

8. Starodubov V. I. Methodological approaches to developing strategic and operational plans of health in the Russian Federation. Moscow: TSNIIOIZ; 2001. 136. Russian (Стародубов В. И. Методические подходы к разработке стратегических и текущих планов здравоохранения в Российской Федерации. М.: ЦНИИОИЗ; 2001. 136).

9. Medik V. A., Tokmachev M. S. Health and Health Statistics Manual. Moscow: Meditsina; 2006: 528. Russian (Медик В. А., Токмачев М. С. Руководство по статистике здоровья и здравоохранения. М.: Медицина; 2006: 528).

10.Fadeev A. B. Reform of the health system of the USSR in the postwar years. Problemy sotsial'noy gigieny, zdravookhraneniya i istorii meditsiny. 2001; 2: 48-50. Russian (Фадеев А. В. Реформа системы здравоохранения СССР в послевоенные годы. Проблемы социальной гигиены, здравоохранения и истории медицины. 2001; 2: 48-50).

11.Hal'fin R. A. Topical issues of the organization of outpatient care to the 
population of the Russian Federation. Zdravookhraneniye. 2003; 10: 19-26. Russian (Хальфин Р. А. Актуальные вопросы организации амбулаторнополиклинической помощи населению Российской Федерации. Здравоохранение. 2003; 10: 19-26).

12.Kucherenko V. Z. Organization and evaluation of the quality of treatment and preventive care: textbook. Moscow: GEOTAR-Media; 2008. 560. Russian (Кучеренко B. 3. Организация и оценка качества лечебнопрофилактической помощи населению: Учебное пособие. М.: ГЭОТАРМедиа; 2008. 560).

13.Myl'nikova L. A. The restructuring of the primary health care as the implementation of the general principles of organization of local government in the Russian Federation. Problemy sotsial'noy gigieny, zdravookhraneniya i istorii meditsiny. 2006; 2: 38-41. Russian (Мыльникова Л. А. Реструктуризация первичного звена здравоохранения как реализация общих принципов организации местного самоуправления в Российской Федерации. Проблемы социальной гигиены, здравоохранения и истории медицины. 2006; 2: 38-41).

14.Shil'nikova N. F., Flek V. O. A typical method of evaluation of outpatient clinics in terms of reform: Metodicheskiye rekomendatsii. Chita: ChGMA; 2004: 32. Russian (Шильникова Н. Ф., Флек В. О. Типовая методика оценки деятельности амбулаторно-поликлинических учреждений в условиях реформы: Методические рекомендации. Чита: ЧГМА; 2004: $32)$.

15.Petrova N. G., Balokhina S. A., Martirosyan M. M. Opinion of patients as an important criterion for the quality of care. Problemy upravleniya zdravookhraneniyem. 2009; 1 (44): 59-61. Russian (Петрова Н. Г., Балохина С. А., Мартиросян М. М. Мнение пациентов как важный критерий качества медицинской помощи. Проблемы управления здравоохранением. 2009; 1 (44): 59-61).

16.Siburina T. A., Lokhtina L. K. Monitoring the implementation of the program 
of state guarantees as a basis for state regulation in the field of public health. Menedzher zdravookhraneniya. 2004; 8: 13-20. Russian (Сибурина T. А., Лохтина Л. $К$. Мониторинг реализации программы государственных гарантий как основа государственного регулирования в сфере здравоохранения. Менеджер здравоохранения. 2004; 8: 13-20).

17.Komarov $Y$ u. M. Primary health care: what it should be? Zdravookhraneniye. 2008; 5: 19-28. Russian (Комаров Ю. М. Первичная медико-санитарная помощь: какой она должна быть? Здравоохранение. 2008; 5: 19-28).

18.Roytman M. P. Lindenbraten A. L. From the new economic mechanism in public health services to the compulsory health insurance. Problemy sotsial'noy gigieny i istoriya meditsiny. 1996; 1: 30-6. Russian (Ройтман М. П., Линденбратен $A$. Л. От нового хозяйственного механизма в здравоохранении к обязательному медицинскому страхованию. Проблемы социальной гигиены и истории медицины. 1996, 1: 30-6).

19.Lavrishcheva G. A., Chernienko E. I. The implementation of the priority national project "Health" in primary care. Zdravookhraneniye. 2011; 3: 163 72. Russian (Лаврищева Г. А., Черниенко Е. И. Реализация приоритетного национального проекта «Здоровье» в первичном звене здравоохранения. Здравоохранение. 2011; 3: 163-72).

20.Martynchik S. A. Organizational basis for monitoring and evaluating the performance of health facilities at the territorial level. Ekonomika zdravookhraneniya. 2007; 11: 77-84. Russian (Мартынчик С. А. Организационные основы мониторинга и оценки эффективности деятельности ЛПУ на территориальном уровне. Экономика здравоохранения. 2007; 11: 77-84). 


\section{INFORMATION ABOUT AUTHORS}

Карайланов Михаил Георгиевич - канд. мед. наук, преподаватель кафедры общественного здоровья и экономики военного здравоохранения, ФГБВОУ ВО «Военно-медицинская академия имени С. М. Кирова» МО РФ, 194044, Санкт-Петербург, ул. Академика Лебедева, д. 6, тел.: +7(911)7728400, e-mail: karaylanov@mail.ru

Karaylanov Mikhail G. - M. D., Ph. D. (Medicine), Lecturer of Public Health and the Economy of the Military Healthcare Department, S. M. Kirov Military Medical Academy the Russian Defense Ministry, 6, Akademika Lebedeva str., Saint Petersburg, Russia, 194044, cont. phone: $+7(911) 7728400$, e-mail: karaylanov@mail.ru

Русев Илья Трифонович - докт. мед. наук, профессор, заведующий кафедрой общественного здоровья и экономики военного здравоохранения, ФГБВОУ ВО «Военно-медицинская академия имени С. М. Кирова» МО РФ, 194044, Санкт-Петербург, ул. Академика Лебедева, д. 6

Rusev Iliya T. - M. D., D. Sc. (Medicine), Prof., the Heat of Public Health and the Economy of the Military Healthcare Department, S. M. Kirov Military Medical Academy the Russian Defense Ministry, 6, Akademika Lebedeva str., Saint Petersburg, Russia, 194044

Борисов Дмитрий Николаевич - канд. мед. наук, подполковник мед. службы, начальник НИЛ (информационных технологий) НИО (медикоинформационных технологий) НИЦ, ФГБВОУ ВО «Военно-медицинская академия имени С. М. Кирова» МО РФ, 194044, Россия, г. Санкт-Петербург, ул. 
Академика Лебедева, д. 6

Borisov Dmitriy N. - M. D., Ph. D. (Medicine), Lieutenant Colonel of the Medical Service, the Heat of Scientific and Research Laboratory of Informatization Research Department (health information technology) Research Center, S. M. Kirov Military Medical Academy the Russian Defense Ministry, 6, Akademika Lebedeva str., Saint Petersburg, Russia, 194044

Баканев Олег Юрьевич — преподаватель, кафедра общественного здоровья и экономики военного здравоохранения, ФГБВОУ ВО «Военномедицинская академия имени С. М. Кирова» МО РФ, 194044, Россия, г. СанктПетербург, ул. Академика Лебедева, д. 6

Bakanev Oleg Yu. - Lecturer of Public Health and the Economy of the Military Healthcare Department, S. M. Kirov Military Medical Academy the Russian Defense Ministry, 6, Akademika Lebedeva str., Saint Petersburg, Russia, 194044

Прокин Игорь Генрихович - канд. мед. наук, доцент кафедры общественного здоровья и экономики военного здравоохранения, ФГБВОУ ВО «Военно-медицинская академия имени С. М. Кирова» МО РФ, 194044, СанктПетербург, ул. Академика Лебедева, д. 6

Prokin Igor G. - Ph. D. (Medicine), Associate Professor of Public Health and Military Health Economics Department, S. M. Kirov Military Medical Academy the Russian Defense Ministry, 6, Akademika Lebedeva str., Saint Petersburg, Russia, 194044 